\title{
New Preparation Method of Visible Light Responsive Titanium Dioxide Photocatalytic Films
}

\author{
Kaori Nishizawa*, Masahisa Okada, Eiji Watanabe \\ Materials Research Institute for Sustainable Development, National Institute of Advanced Industrial Science \\ and Technology (AIST), Nagoya, Japan \\ Email: ${ }^{*}$-nishizawa@aist.go.jp
}

Received 25 December 2013; revised 29 January 2014; accepted 16 February 2014

Copyright $(02014$ by authors and Scientific Research Publishing Inc.

This work is licensed under the Creative Commons Attribution International License (CC BY). http://creativecommons.org/licenses/by/4.0/

(c) (i) Open Access

\begin{abstract}
We report a new and simple preparation method of the visible light responsive Titanium dioxide $\left(\mathrm{TiO}_{2}\right)$ photocatalytic films using sol-gel method and ultraviolet light (UV) irradiation. Proposed films were prepared on fused silica plates using titanium tetra-isopropoxide, urea, 2-methoxyethanol, water and $\mathrm{UV}$ irradiation. The $650^{\circ} \mathrm{C}$-annealed films were carbon-containing anatase type $\mathrm{TiO}_{2}$, not carbon-doped ones. The prepared films absorbed visible light with wavelengths longer than $400 \mathrm{~nm}$. Also, organic dyes were effectively photodegradated by visible light irradiation in the presence of these films.
\end{abstract}

\section{Keywords}

Titanium Dioxide Films; Sol-Gel Method; UV Irradiation; Visible Light Responsive Photocatalyst

\section{Introduction}

Titanium dioxide $\left(\mathrm{TiO}_{2}\right)$ has been widely studied for many applications, such as paints, cloth fibers, cosmetics and microelectronics, optical cells, solar energy conversion, photocatalyst for environmental purification and production of hydrogen gas, and so on. This is because $\mathrm{TiO}_{2}$ is a cheap material and shows nontoxicity, high activities and chemical stability. In particular, various anatase type $\mathrm{TiO}_{2}$ powders and films have been fabricated for development of photocatalytic activities such as strong organic degradation and superhydrophilicity [1]-[6]. However, photocatalytic reactions by $\mathrm{TiO}_{2}$ only proceed under ultraviolet (UV) irradiation, but do not proceed

*Corresponding author.

How to cite this paper: Nishizawa, K., Okada, M. and Watanabe, E. (2014) New Preparation Method of Visible Light Responsive Titanium Dioxide Photocatalytic Films. Materials Sciences and Applications, 5, 112-123. 
under visible light irradiation. That is because the anatase type pure $\mathrm{TiO}_{2}$ only absorbs UV light with wavelength shorter than $380 \mathrm{~nm}$, based on its wide band gap (3.0 - $3.2 \mathrm{eV})$. However, UV light accounts for only about several \% of solar energy. In addition, UV light responsive photocatalysts had been limited for use in the room because there are not a lot of UV lights in the room.

Recently, many attempts to develop the effective photocatalysts for the visible light region have been done [7]-[11]. That is, a lot of visible light responsive $\mathrm{TiO}_{2}$ photocatalysts, whose photocatalytic reaction can proceed under visible light, have been developed by doping something elements to the $\mathrm{TiO}_{2}$ crystal lattice or reduction of $\mathrm{TiO}_{2}$. The shift of the optical response of $\mathrm{TiO}_{2}$ from UV to the visible spectral range will have a profound positive effect on the efficient use of solar energy in photocatalytic reactions and the use in the room. The doping of $\mathrm{TiO}_{2}$ is currently attracting considerable interest as a promising route to extend the optical absorption of this material to visible spectral region. One promising approach to synthesizing visible light active photocatalysts is the substitution of Ti by transition metals, such as V, Cr, Ni, or Fe, and so on [12]-[15]. However, most of these metal-doped $\mathrm{TiO}_{2}$ do not show long-term stability or do not have sufficient activities for wide range of applications. Another promising approach is the doping of nonmetal atoms, such as N, S, or C [16]-[21]. The nonmetal atoms doping have been reported to be more effective for the band gap narrowing of $\mathrm{TiO}_{2}$ than transition metal doping [19] [20]. That is because their impurity levels are near the valence band edge of $\mathrm{TiO}_{2}$. Therefore, they do not act as charge carriers and their roles as recombination centers are minimized compared to the metal doping [13] [19] [20]. As a famous example of nonmetal doping, Asahi and co-workers proposed that substitutionaltype $\mathrm{N}$ doping was effective for the band gap narrowing of $\mathrm{TiO}_{2}$ due to the mixing of $\mathrm{N} 2 \mathrm{p}$ with $\mathrm{O} 2 \mathrm{p}$ states in the valence band [16]. As for the investigation of $\mathrm{TiO}_{2}$ modified with $\mathrm{C}$, it has been reported some types of $\mathrm{TiO}_{2}$ such as substitutional C-doped $\mathrm{TiO}_{2}$, interstitial carbonate-doped $\mathrm{TiO}_{2}$ and highly condensed coke-like carbon containing $\mathrm{TiO}_{2}$ and so on [21]-[34]. It is reported that the $\mathrm{TiO}_{2}$ modified with $\mathrm{C}$ induce the visible light absorption by band gap narrowing or a role as photosensitizer like organic dyes. In these ways, the design of the electronic structure or the chemical modification of metal oxides was very effective for controlling their optical properties. However, an expensive apparatus was used or there were some safety hazard in these proposed methods.

On the other hand, the sol-gel method is one of the suitable and simple techniques for preparation of metal oxide films. In addition, it is also suited to design the network formation of metal oxide precursors, resulting in materials with special optical and catalytic properties. Furthermore, UV irradiation of metal oxide gel films is effective for the decomposition of organic compounds in the films or improvement of crystallinity of the films, and so on [35]-[38]. In this paper, we report a safety and simple preparation method of the visible light responsive $\mathrm{TiO}_{2}$ photocatalytic films by sol-gel and UV irradiation method.

\section{Materials and Methods}

\subsection{Preparation of $\mathrm{TiO}_{2}$ Precursor Sol Solutions}

All chemicals used in this study were of analytical grade and were used without further purification. The preparation methods of $\mathrm{TiO}_{2}$ precursor sol solutions (a)-(d) were as follows: The $0.25 \mathrm{~mol} / \mathrm{dm}^{3}$ titanium-tetra-isopropoxide $\left(\mathrm{Ti}(\mathrm{O}-\mathrm{i}-\mathrm{Pr})_{4}\right)$ was dissolved in 2-methoxyethanol under dry argon gas. Then urea was added to the solution and it was refluxed at $130^{\circ} \mathrm{C}$ for 3 hours. After cooling the solution to room temperature, UV light (250 W ultra-high pressure mercury lamp, $100 \mathrm{~mW} / \mathrm{cm}^{2}$ at $365 \mathrm{~nm}$ ) was irradiated to the sol solution for 4 hours in the air at room temperature. After that, a small amounts of distilled water was added to it and it was stirred for one night. The preparation conditions of sol solutions were shown in Table 1.

\subsection{Preparation of $\mathrm{TiO}_{2}$ Films}

Fused silica plates $(25 \times 25 \times 1 \mathrm{~mm})$ were used as support substrates. The fused silica plate was dipped into the $\mathrm{TiO}_{2}$ precursor sol solution. The dipped plate was withdrawn from the solution at the rate of $0.5 \mathrm{~mm} / \mathrm{s}$. The dip-coated films were dried at room temperature for $30 \mathrm{~s}$ and then dried at $100^{\circ} \mathrm{C}$ for $30 \mathrm{~min}$. After drying, the films were heated at the rate of $10^{\circ} \mathrm{C} / \mathrm{min}$ and annealed at $650^{\circ} \mathrm{C}$ for 1 hour in the air.

\subsection{Characterization}

The crystal structures of the films were identified by thin film X-ray diffraction (XRD: MPX, Mac Science) 
Table 1. Preparation conditions of $\mathrm{TiO}_{2}$ precursor sol solutions and films.

\begin{tabular}{cccccc}
\hline $\mathbf{T i O}_{2}$ films & Sol & $\mathbf{T i}(\mathbf{O}-\mathbf{i}-\mathbf{P r})_{\mathbf{4}}\left(\mathbf{m o l} / \mathbf{d m}^{3}\right)$ & Urea $\left(\mathbf{m o l} / \mathbf{d m}^{3}\right)$ & $\mathbf{H}_{2} \mathbf{O}\left(\mathbf{m o l} / \mathbf{d m}^{3}\right)$ & UV irradiation \\
\hline (A) & (a) & 0.25 & 0.5 & 0.5 & Irradiated \\
(B) & (b) & 0.25 & 0 & 0.5 & Irradiated \\
(C) & (c) & 0.25 & 0.5 & 0.5 & Non \\
(D) & (d) & 0.25 & 0 & 0.5 & Non \\
\hline
\end{tabular}

measurements using CuK $\alpha$ radiation. The acceleration voltage and current were $40 \mathrm{kV}$ and $30 \mathrm{~mA}$, respectively. The UV-visible (UV-vis) absorption spectra of the films were taken on a Hitachi U-4100. Elemental analysis of $\mathrm{C}, \mathrm{H}$, and $\mathrm{N}$ in the dried and annealed gels was carried out in an elemental analyzer Thermo Finnigan Flash EA 1112. The dried gels were prepared by vacuum drying of the sols at room temperature and the annealed gels were prepared by sintering of the dried gels at $650^{\circ} \mathrm{C}$ for 1 hour. X-ray photoelectron spectroscopy measurements of the films were carried out using a Sigmaprobe spectrometer (XPS: Thermo Electron) with MgK $\alpha$ X-ray $(h v=1254 \mathrm{eV})$ radiation to investigate the surface properties. The shift of the binding energy due to relative surface changing was corrected using the $\mathrm{C} 1 \mathrm{~s}$ level at $284.5 \mathrm{eV}$ as an internal standard. $\mathrm{Ar}^{+}$etching was applied to clean the surface of samples and to measure the depth profiles. The estimated etch rate of the ion gun was expected to be about $0.05 \mathrm{~nm} / \mathrm{s}$ for the $\mathrm{TiO}_{2}$ thin films [39]. ${ }^{1} \mathrm{H}-\mathrm{NMR}$ spectra of the $\mathrm{TiO}_{2}$ precursor dried gels were recorded on a Varian INOVA300 spectrometer in $\mathrm{CDCl}_{3}$.

\subsection{Photocatalytic Evaluation of $\mathrm{TiO}_{2}$ Films}

The photocatalytic activities of prepared $\mathrm{TiO}_{2}$ films were evaluated by examining photodecomposition of methylene blue (MB). The substrates coated with $\mathrm{TiO}_{2}$ films were placed in a $1.0 \times 10^{-2} \mathrm{mmol} / \mathrm{dm}^{3}$ aqueous solution containing MB for 18 hours under dark. Then the solutions were irradiated with visible light (wavelength: 410 - $520 \mathrm{~nm}$ ). Used lamp was $250 \mathrm{~W}$ ultra-high pressure mercury lamp (UHPML: multilight UIV-270, Ushio) and two pieces of glass filters were used for selection of wavelength (No. 3-73 and 7-59, Corning). The concentration change of MB by visible light irradiation was evaluated by monitoring $665 \mathrm{~nm}$ absorbance using the UV-vis light spectrometer U-4100 at hourly intervals.

\section{Results and Discussion}

\subsection{Characterization of the $\mathrm{TiO}_{2}$ Films}

Figure 1 shows the XRD patterns of $\mathrm{TiO}_{2}$ films (A)-(D) prepared using the sol solutions (a)-(d). For each sample, all peaks were indexed to the anatase phase of $\mathrm{TiO}_{2}$ (JCPDS file No. 21-1272). The average crystallite sizes were calculated using (101) diffraction peaks according to the Scherrer equation. The crystallite sizes of all films were almost the same, ca $18 \mathrm{~nm}$.

Figure 2(a) shows UV-vis absorption spectra of $\mathrm{TiO}_{2}$ films (A)-(D). A strong absorption assigned to the band-band transition can be observed in the ultraviolet region for all samples. In addition, all $\mathrm{TiO}_{2}$ films absorbed not only UV light, but also visible light with wavelength longer than $400 \mathrm{~nm}$. In particular, the absorbance of the $\mathrm{TiO}_{2}$ film (A) prepared using the sol solution (a) was higher than that of the films (B)-(D). Assuming the materials to be an indirect semiconductor, the band gap energies of films were estimated from the intercept of the tangents to the plots of $(\alpha h v)^{1 / 2}$ versus photon energy $h v$ as shown in Figure 2(b) [21]. The optical band gap energies of all films estimated from the plots of Figure 2(b) were around $3.2 \mathrm{eV}$. It is known that the band gap energy of anatase type $\mathrm{TiO}_{2}$ is $3.2 \mathrm{eV}$. Accordingly, it was expected that the visible light absorptions in these films were not due to band gap narrowing.

The CHN elemental analysis of $650^{\circ} \mathrm{C}$-annealed $\mathrm{TiO}_{2}$ powder samples was carried out in order to examine the reasons of visible light absorption as shown in Table 2 . The found values of elemental analysis were C: $0.12 \%$ $0.23 \%$, $\mathrm{H}: 0.00 \%$ and $\mathrm{N}: 0.00 \%$ in all samples. The visible light absorption of $\mathrm{TiO}_{2}$ will be due to carbon species including in the films.

The XPS measurements were carried out to determine the chemical state of elements around the surface of films in details. Figure 3 shows N1s spectra of films (A)-(D). Broad energy bands were observed in the range 


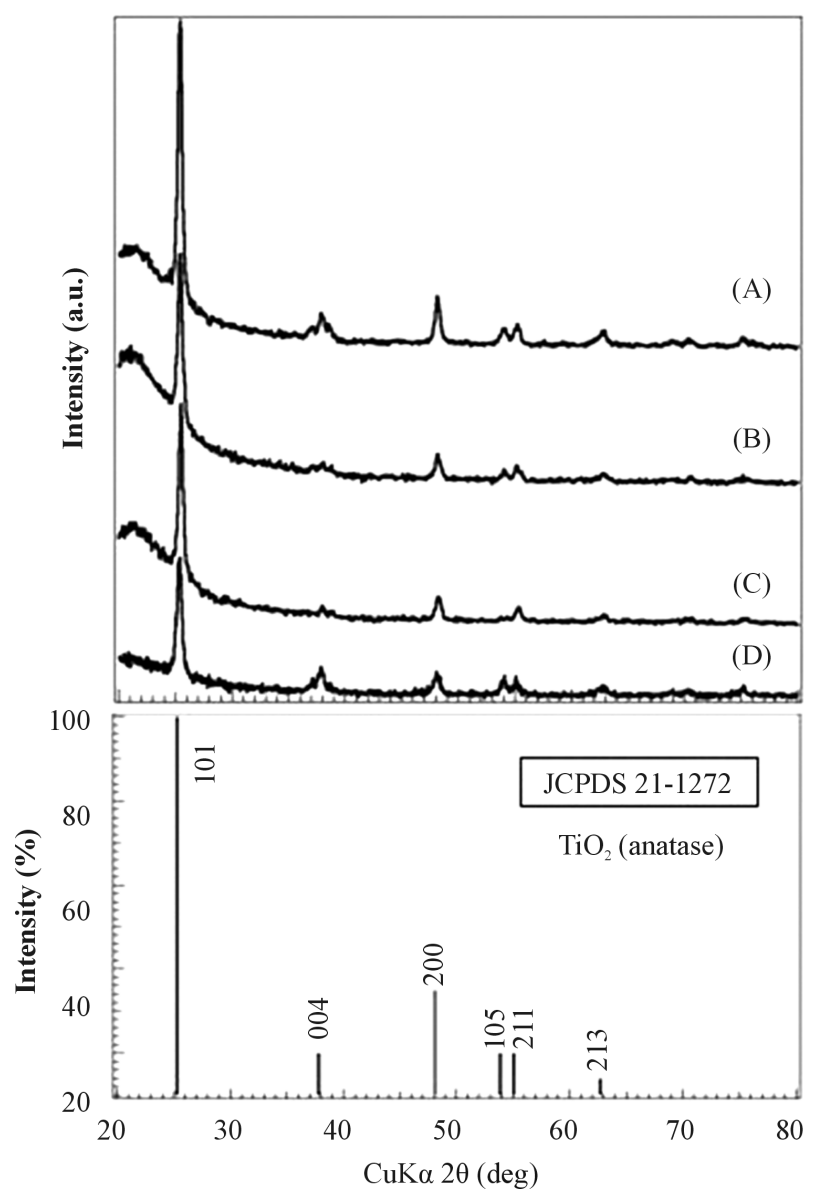

Figure 1. XRD patterns of sol-gel derived $\mathrm{TiO}_{2}$ films. (A) $\mathrm{TiO}_{2}$ film which was made from the sol solution (a); (B) $\mathrm{TiO}_{2}$ film which was made from the sol solution (b); (C) $\mathrm{TiO}_{2}$ film which was made from the sol solution (c); (D) $\mathrm{TiO}_{2}$ film which was made from the sol solution (d).

Table 2. The CHN elemental analysis of $\mathrm{TiO}_{2}$ annealed at $650^{\circ} \mathrm{C}$.

\begin{tabular}{cccc}
\hline \multirow{2}{*}{ Sol solution } & \multicolumn{3}{c}{$\mathbf{6 5 0}^{\circ} \mathbf{C}$-annealed $\mathbf{T i O}_{2}$} \\
\cline { 2 - 4 } & $\mathbf{C ~ ( \% )}$ & $\mathbf{H}(\%)$ & $\mathbf{N}(\%)$ \\
\hline (a) & 0.23 & 0.00 & 0.00 \\
(b) & 0.20 & 0.00 & 0.00 \\
(c) & 0.16 & 0.00 & 0.00 \\
(d) & 0.12 & 0.00 & 0.00 \\
\hline
\end{tabular}

from 404 to $396 \mathrm{eV}$ before surface etching (etching time $0 \mathrm{~s}$ ). However, these bands disappeared after surface etching for $20 \mathrm{~s}$ (ca. $1 \mathrm{~nm}$ etching from the surface). From the results, broad N1s bands around $400 \mathrm{eV}$ can be assigned to adventitious nitrogen species on the surface. Accordingly, it was clear that nitrogen is not included in the films. The results of N1s spectra agreed with those of the elemental analysis. Figure 4 shows C1s spectra of films (A)-(D). Broad energy bands were observed in the range from 290 to $282 \mathrm{eV}$ before surface etching (etching time $0 \mathrm{~s}$ ). The peaks around 289, 286 and $284.5 \mathrm{eV}$ for all films before surface etching can be assigned to adventitious carbon species, $\mathrm{C}=\mathrm{O}$ of $\mathrm{CO}_{3}^{2+}, \mathrm{C}-\mathrm{O}$ and $\mathrm{C}-\mathrm{C}$, respectively [21] [25]. After surface etching for $20 \mathrm{~s}$, adventitious carbon species on the surface disappeared and new peaks appeared around $283.5 \mathrm{eV}$. Accord- 

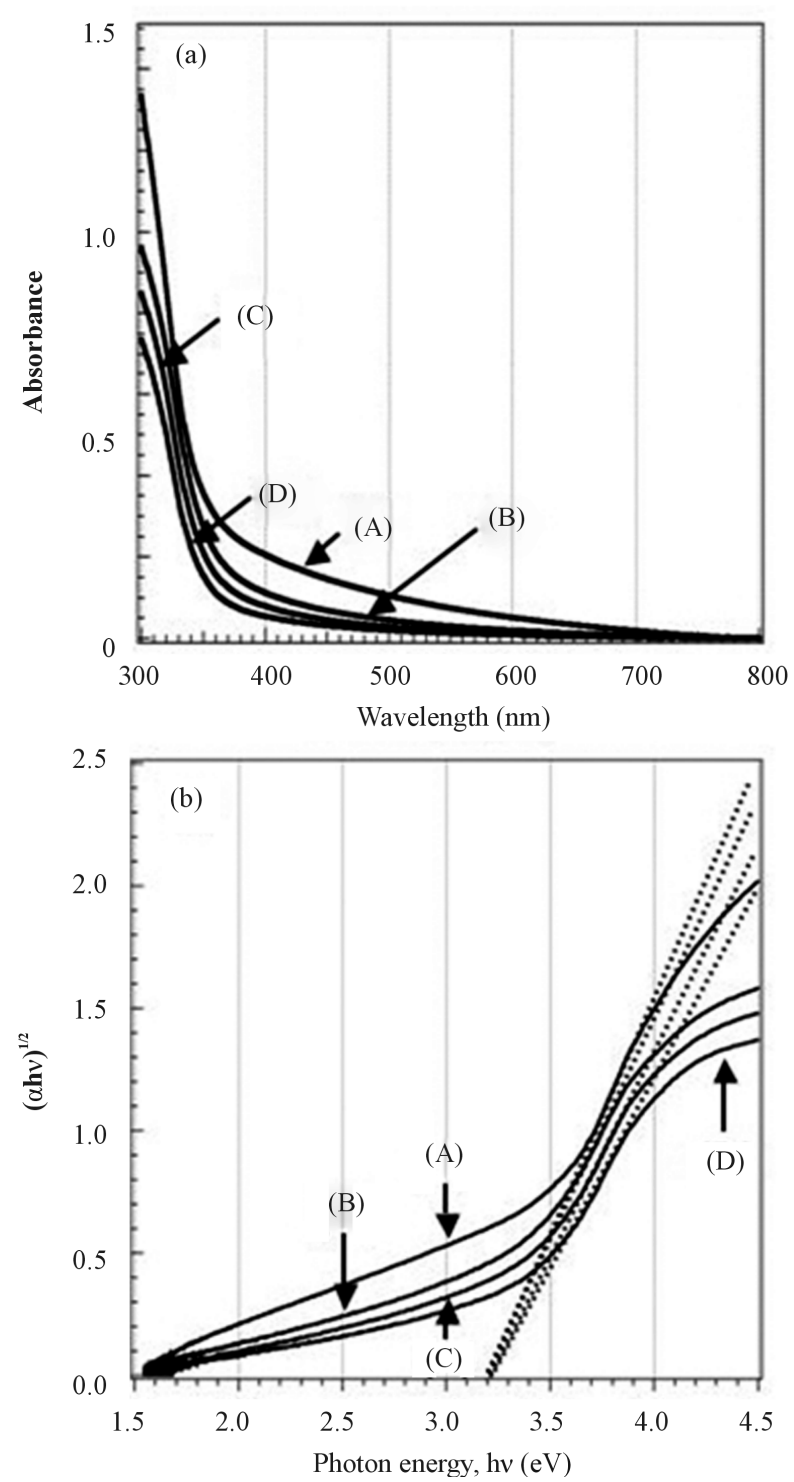

Figure 2. UV-vis absorption spectra (a) and plots of $(\alpha h v)^{1 / 2}$ versus photon energy $(h v)$ (b) of sol-gel derived $\mathrm{TiO}_{2}$ films. (A) $\mathrm{TiO}_{2}$ film which was made from the sol solution (a); (B) $\mathrm{TiO}_{2}$ film which was made from the sol solution (b); (C) $\mathrm{TiO}_{2}$ film which was made from the sol solution (c); (D) $\mathrm{TiO}_{2}$ film which was made from the sol solution (d).

ing to the literatures, it has been reported that there are highly condensed coke-like carbon originated from another C-C species, that is, Ti-alkoxide derived C-C species in the films in the case of sol-gel method using alkoxide precursors [22] [27]. Thus, it was suggested that the new peaks around $283.5 \mathrm{eV}$ were originated from Ti-alkoxide derived C-C species that were different from adventitious carbon species. Furthermore, the peak around $283.5 \mathrm{eV}$ of film (A) was greater than those of films (B)-(D) in the case of surface etching for $20 \mathrm{~s}$. In addition, the peak around $283.5 \mathrm{eV}$ of film (A) after surface etching for $140 \mathrm{~s}$ (ca. $7 \mathrm{~nm}$ etching from the surface) got larger than that after surface etching for $20 \mathrm{~s}$. From the results of Figures 2, 4 and Table 2, it was found that the visible light absorption got stronger with increasing of the amounts of $\mathrm{C}$ species in the sample. These results agreed with an earlier report [20] [27]. On the other hand, new small peaks appeared around $281 \mathrm{eV}$ for all films after etching for $140 \mathrm{~s}$. The peak around $281 \mathrm{eV}$ can be assigned to Ti-C species [21] [24] [25]. It was expected that the oxygen sites of $\mathrm{TiO}_{2}$ lattice were substituted by carbon atoms and $\mathrm{Ti}-\mathrm{C}$ structures were formed in the 


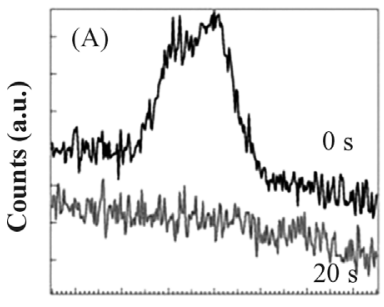

406404402400398396394 Binding Energy (eV)

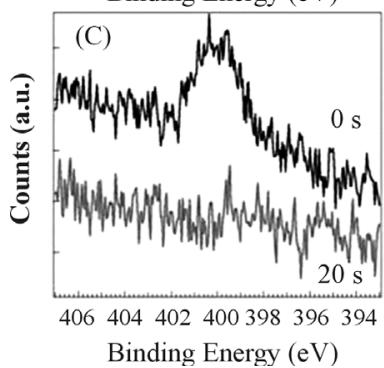

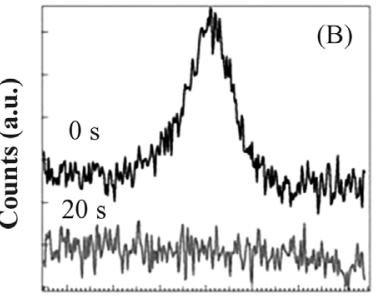

406404402400398396394 Binding Energy (eV)

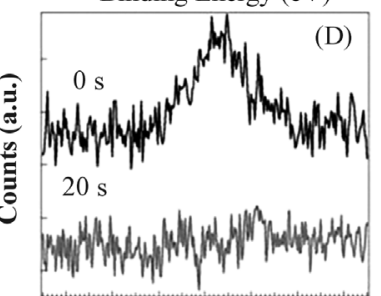

406404402400398396394 Binding Energy $(\mathrm{eV})$

Figure 3. XPS spectra of N1s of sol-gel derived $\mathrm{TiO}_{2}$ films. The digits, $0 \mathrm{~s}$ and $20 \mathrm{~s}$, in figures show etching time. (A) $\mathrm{TiO}_{2}$ film which was made from the sol solution (a); (B) $\mathrm{TiO}_{2}$ film which was made from the sol solution (b); (C) $\mathrm{TiO}_{2}$ film which was made from the sol solution (c); (D) $\mathrm{TiO}_{2}$ film which was made from the sol solution (d).
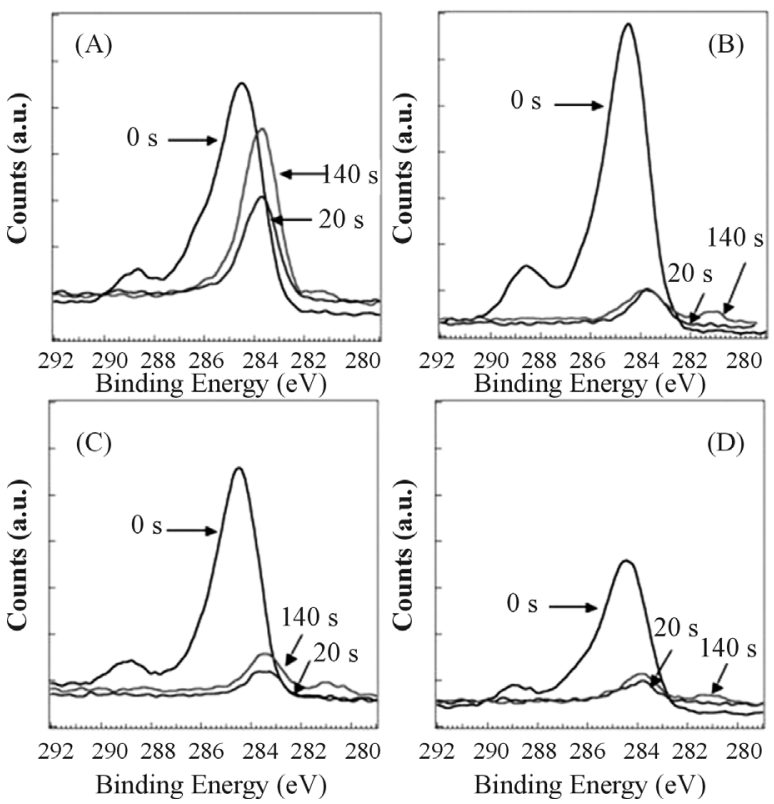

Figure 4. XPS spectra of $\mathrm{C} 1 \mathrm{~s}$ of sol-gel derived $\mathrm{TiO}_{2}$ films. The digits, $0 \mathrm{~s}, 20 \mathrm{~s}$ and $140 \mathrm{~s}$, in figures show etching time. (A) $\mathrm{TiO}_{2}$ film which was made from the sol solution (a); (B) $\mathrm{TiO}_{2}$ film which was made from the sol solution (b); (C) $\mathrm{TiO}_{2}$ film which was made from the sol solution (c); (D) $\mathrm{TiO}_{2}$ film which was made from the sol solution (d).

crystal lattice. However, it might not be effective for the visible light absorption because a quantity of Ti-C species formed in the crystal lattice was very few and the formed Ti-C species were not in the surface. Therefore, it was expected that the visible light absorption of $\mathrm{TiO}_{2}$ is due to photosensitization by coke-like carbon formed in 
the films [20]-[22] [27] [28]. In the literature [21], it has been reported that two possible pathways ascribed to band gap narrowing by carbon doping and to carbon photosensitization are not involved in the photoreaction for single-nonmetal doped $\mathrm{TiO}_{2}$. The results in this paper accorded with the former report.

\subsection{Formation Mechanism of Carbon-Containing $\mathrm{TiO}_{2}$}

Formation mechanism of carbon-containing $\mathrm{TiO}_{2}$ will be considered as follows: $\mathrm{Ti}(\mathrm{O}-\mathrm{i}-\mathrm{Pr})_{4}$ was easy to be hydrolyzed by $\mathrm{H}_{2} \mathrm{O}$ addition and form precipitations in the solution in the case of using isopropyl alcohol as a reaction solvent. However, $\mathrm{Ti}(\mathrm{O}-\mathrm{i}-\mathrm{Pr})_{4}$ formed a stable and homogeneous $\mathrm{TiO}_{2}$ precursor sol without precipitating in the solution after $\mathrm{H}_{2} \mathrm{O}$ addition in the case of using 2-methoxyethanol as a reaction solvent. From these phenolmena, it was expected that $\mathrm{Ti}(\mathrm{O}-\mathrm{i}-\mathrm{Pr})_{4}$ caused solvent exchange reaction and/or alcoholysis reaction with 2-methoxyethanol, that is, 2-methoxyethanol attached to the titanium metal center [40]-[43]. As a result, the sixcoordinated Ti complexes were formed in the reaction and stabilized for hydrolysis.

Table 3 shows the colors of prepared sol solution and results of the CHN elemental analysis of $\mathrm{TiO}_{2}$ precursor gels dried in a vacuum oven at room temperature. The sol solution prepared without urea remained transparent after $\mathrm{H}_{2} \mathrm{O}$ addition as shown in Tables 3(b) and (d). It has shown that these solutions are stabilized for hydrolysis. That will be because Ti(O-i-Pr $)_{4}$ caused solvent exchange reaction and/or alcoholysis reaction with 2-methoxyethanol as described above. Furthermore, the color of sol solution prepared without urea has changed from clear transparent to yellow transparent after UV irradiation (Tables 3(b) and (d)). Considering the ligand field theory, the result may be because division width of the $d$-orbitals in titanium became narrow by change of ligand field, that is, ligands of titanium fully exchanged from isopropoxides to 2-methoxyethoxides by UV irradiation [44]-[47]. According to ${ }^{1} \mathrm{H}-\mathrm{NMR}$ spectra, the doublet peak at $1.25 \mathrm{ppm}$ originated from methyl groups of isopropoxides disappeared by irradiating UV light as shown in Figure 5. From the result, it was suggested that the ligand substitution reaction occurred by UV irradiation. In addition, carbon contents in the dried gel and the annealed $\mathrm{TiO}_{2}$ prepared from sol solution (b) with UV irradiation were more than those in the dried gel and the annealed $\mathrm{TiO}_{2}$ prepared from sol solution (d) without UV irradiation as shown in Tables 2 and 3. It may be because eliminated organic ligands (isopropoxides) were decomposed and condensed as cokes in the gels by UV irradiation.

On the other hand, the rate of hydrolysis and gelation for the sol solutions prepared using urea (Tables 3(a) and (c)) was faster than that for the sol solutions prepared without urea (Tables 3(b) and (d)). In addition, the dried gels prepared with urea have included nitrogen as shown in Tables 3(a) and (c). According to the literatures [48]-[50], it has been reported that urea coordinates to titanium through weak $\mathrm{C}=\mathrm{O} \rightarrow \mathrm{Ti}$ coordination bonding with remaining the carbonyl groups. Therefore, it was expected that the sites coordinated by urea are

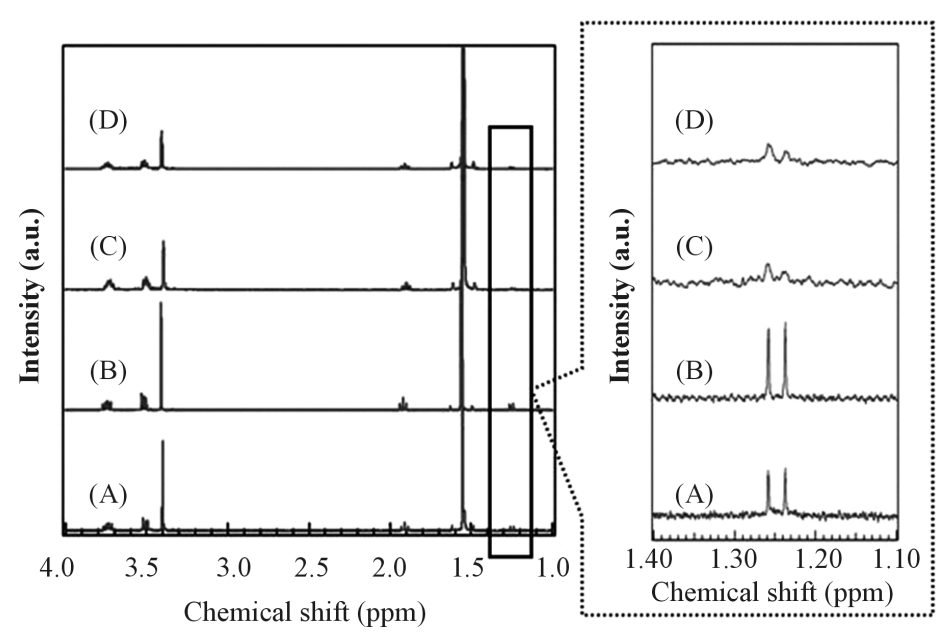

Figure 5. ${ }^{1} \mathrm{H}$-NMR spectra of the $\mathrm{TiO}_{2}$ precursor dried gels prepared without urea. (A) Dried gel before UV irradiation and without $\mathrm{H}_{2} \mathrm{O}$ addition; (B) Dried gel prepared without UV irradiation and with $\mathrm{H}_{2} \mathrm{O}$ addition; (C) Dried gel prepared after UV irradiation and without $\mathrm{H}_{2} \mathrm{O}$ addition; (D) Dried gel prepared after UV irradiation and with $\mathrm{H}_{2} \mathrm{O}$ addition. 
easy to be hydrolyzed by $\mathrm{H}_{2} \mathrm{O}$. Furthermore, nitrogen and carbon contents in the dried gels increased by UV irradiation (Tables 3(a) and (c)). According to ${ }^{1} \mathrm{H}$-NMR spectra, the ratio of integral value of peak assigned to $\mathrm{NH}_{2}$ groups in urea and that of $\mathrm{OCH}_{3}$ groups in 2-methoxyethoxides became larger by UV irradiation. From the results, in the case of the samples prepared using urea, it was suggested that ligands of titanium changed from 2-methoxyethoxides to urea by UV irradiation. After that, the released organic ligands were decomposed and condensed by UV irradiation, coke-like carbon would have been formed in the gels. About nitrogen, it was expected that urea eliminated by hydrolysis was decomposed after annealing and nitrogen species released completely from the gels. In this way, it was suggested that $\mathrm{TiO}_{2}$ became able to absorb the visible light because the carbon contents in the $\mathrm{TiO}_{2}$ improved by urea addition and UV irradiation.

\subsection{Photocatalytic Evaluation of $\mathrm{TiO}_{2}$ Films}

In order to evaluate the photocatalytic activities of the prepared $\mathrm{TiO}_{2}$ films toward visible light irradiation, the absorbance change of $\mathrm{MB}$ at $665 \mathrm{~nm}$ was monitored as a function of visible light irradiation time. Figure 6 shows plots of $\ln \left(\mathrm{C} / \mathrm{C}_{0}\right)$ vs irradiation time $t$, where $\mathrm{C}_{0}$ and $\mathrm{C}$ are the concentrations of $\mathrm{MB}$ at $t=0$ and $t=t$, respectively. Concentrations of $\mathrm{MB}$ were calculated from the absorbance. $\mathrm{MB}$ aqueous solutions immersing $\mathrm{TiO}_{2}$

Table 3. The colors of $\mathrm{TiO}_{2}$ precursor sol solution and the CHN elemental analysis of $\mathrm{TiO}_{2}$ precursor gels dried in a vacuum oven at room temperature.

\begin{tabular}{ccccc}
\hline \multirow{2}{*}{ Sol solution } & Sol color & \multicolumn{3}{c}{ Dried gel } \\
\cline { 3 - 5 } & & $\mathrm{C}(\%)$ & $\mathrm{H}(\%)$ & $\mathrm{N}(\%)$ \\
\hline (a) & Milky yellow (gelation) & 18.4 & 4.9 & 21.5 \\
(b) & Yellow transparent & 14.4 & 3.5 & 0.0 \\
(c) & Milky white (gelation) & 18.0 & 4.8 & 17.0 \\
(d) & Clear transparent & 13.5 & 3.4 & 0.0 \\
\hline
\end{tabular}

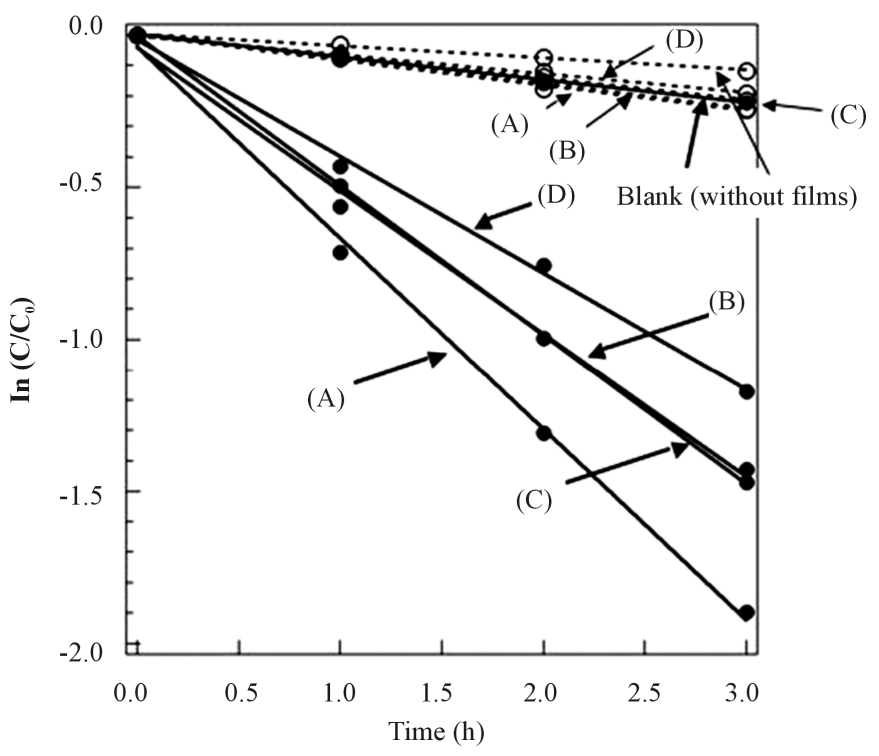

Figure 6. Photocatalytic activities of sol-gel derived $\mathrm{TiO}_{2}$ films under visible light irradiation (wavelength: 410 - $600 \mathrm{~nm}$ ). Dotted lines show the concentration changes of methylene blue under dark. (A) $\mathrm{TiO}_{2}$ film which was made from the sol solution (a); (B) $\mathrm{TiO}_{2}$ film which was made from the sol solution (b); (C) $\mathrm{TiO}_{2}$ film which was made from the sol solution (c); (D) $\mathrm{TiO}_{2}$ film which was made from the sol solution (d). 
films (A)-(D) were clearly photo-bleached by visible light irradiation. The photo-bleaching of MB is caused by photo-oxidative decomposition derived from electron holes on valence band of $\mathrm{TiO}_{2}$ or photo-reduction derived from electrons photo-generated on conduction band of $\mathrm{TiO}_{2}$. Generally, it is reported that photo-reduction is difficult to occur because the electrons photo-generated and excited from valence band to conduction band are trapped by $\mathrm{O}_{2}$ in the air [2] [4] [51] [52]. Therefore, photo-oxidative decomposition is easy to be caused by electron holes on valence band of $\mathrm{TiO}_{2}$ instead. When photo-reduction of $\mathrm{MB}$ occurs, a new peak originated from reduction form of MB is observed at $256 \mathrm{~nm}$ in the UV-visible absorption spectra. In this experiment, the new peak at $256 \mathrm{~nm}$ did not appear together with photo-bleaching of MB. Therefore, the photo-bleaching in this experiment was judged to be due to the photo-oxidative decomposition. The photo-oxidative decomposition of MB in the presence of the $\mathrm{TiO}_{2}$ films obeyed good first-order kinetics. The apparent rate constant was obtained from the slop of the straight line, which was strongly dependent on the visible light absorbance of films as shown in Figure 6. In particular, the decomposition rate of $\mathrm{MB}$ in the presence of the film (A) was faster than that of the other films (B)-(D). In this way, the $\mathrm{TiO}_{2}$ films prepared by these methods showed visible light responsive photocatalytic activities.

On the other hand, upon illumination in the absence of the photocatalytic films, the concentration of MB slightly decreased with increasing of visible light irradiation time. This fact meant that MB itself slightly absorbed visible light in this region and was a little photo-bleached. According to the UV-visible absorption spectral measurement of $\mathrm{MB}$, the phenomena were suggested to be due to the photodecomposition of MB. Moreover, the concentration changes of $\mathrm{MB}$ aqueous solutions under dark were measured and shown in dotted lines of this figure. Also under dark, the concentration of $\mathrm{MB}$ slightly decreased over time in the solution immersing $\mathrm{TiO}_{2}$ films (A)-(D) and without films (blank). From the results, MB has been slightly removed from the liquid phase just by their adsorption on $\mathrm{TiO}_{2}$ films and/or the glass beaker surface. However, their influence can be omitted because the amounts of the photo-absorption of MB itself and the adsorption of MB on the surface are little.

\section{Conclusion}

Carbon-containing $\mathrm{TiO}_{2}$ films were prepared using the four types of sol solutions. All films were anatase type $\mathrm{TiO}_{2}$ and absorbed visible light with wavelength longer than $400 \mathrm{~nm}$ effectively. In addition, the photocatalytic activities of the films under visible light $(410$ - $520 \mathrm{~nm}$ ) irradiation were confirmed by evaluation of the MB decomposition. The sol-gel method using urea addition and UV irradiation was simple and effective method for the fabrication of visible light responsive $\mathrm{TiO}_{2}$ photocatalyst.

\section{Acknowledgements}

We would like to thank Dr. Masakazu Nishida, National Institute of Advanced Industrial Science and Technology (AIST), for helpful technical advices in relation to ${ }^{1} \mathrm{H}-\mathrm{NMR}$ spectral measurement.

\section{References}

[1] Fujishima, A. and Honda, K. (1972) Electrochemical Photolysis of Water at a Semiconductor Electrode. Nature, 238, 37-38. http://dx.doi.org/10.1038/238037a0

[2] Jaeger, C.D. and Bard, A.J. (1979) Spin Trapping and Electron Spin Resonance Detection of Radical Intermediates in the Photodecomposition of Water at $\mathrm{TiO}_{2}$ Particles Systems. The Journal of Physical Chemistry A, 83, 3146-3152. http://dx.doi.org/10.1021/j100487a017

[3] O’Regan, B. and Gratzel, M. (1991) A Low-Cost, High-Efficiency Solar Cell Based on Dye-Sensitized Colloidal TiO 2 Films. Nature, 353, 737-740. http://dx.doi.org/10.1038/353737a0

[4] Hoffmann, M.R., Martin, S.T., Choi, W. and Bahnemann, D.W. (1995) Enviromental Applications of Semiconductor Photocatalysis. Chemical Reviews, 95, 69-96. http://dx.doi.org/10.1021/cr00033a004

[5] Wang, R., Hashimoto, K., Fujishima, A., Chikuni, M., Kojima, E., Kitamura, A., Shimohigoshi, M. and Watanabe, T. (1997) Light-Induced Amphiphilic Surfaces. Nature, 388, 431-432. http://dx.doi.org/10.1038/41233

[6] Khan, S.U.M., Al-Shahry, M. and Ingler Jr., W.B. (2002) Efficient Photochemical Water Splitting by a Chemically Modified n- $\mathrm{TiO}_{2}$. Science, 297, 2243-2245. http://dx.doi.org/10.1126/science.1075035

[7] Serpone, N., Maruthamuthu, P., Pichat, P., Pelizzetti, E. and Hidaka, H. (1995) Exploiting the Interparticle Electron Transfer Process in the Photocatalysed Oxidation of Phenol, 2-Chlorophenol and Pentachlorophenol: Chemical Evidence for Electron and Hole Transfer between Coupled Semiconductors. Journal of Photochemistry and Photobiology 
A: Chemistry, 85, 247-255. http://dx.doi.org/10.1016/1010-6030(94)03906-B

[8] Sakatani, Y., Nunoshige, J., Ando, H., Okusako, K., Koike, H., Takata, T., Kondo, J.N., Hara, M. and Domen, K. (2003) Photocatalytic Decomposition of Acetaldehyde under Visible Light Irradiation over $\mathrm{La}^{3+}$ and N Co-doped $\mathrm{TiO}_{2}$. Chemistry Letters, 32, 1156-1157. http://dx.doi.org/10.1246/cl.2003.1156

[9] Gole, J.L., Stout, J.D., Burda, C., Lou, Y. and Chen, X. (2004) Highly Efficient Formation of Visible Light Tunable $\mathrm{TiO}_{2-\mathrm{x}} \mathrm{N}_{\mathrm{x}}$ Photocatalysts and Their Transformation at the Nanoscale. The Journal of Physical Chemistry B, 108, 12301240. http://dx.doi.org/10.1021/jp030843n

[10] Miyauchi, M., Takashio, M. and Tobimatsu, H. (2004) Photocatalytic Activity of $\mathrm{SrTiO}_{3}$ Co-doped with Nitrogen and Lanthanum under Visible Light Illumination. Langmuir, 20, 232-236. http://dx.doi.org/10.1021/la0353125

[11] Nakamura, I., Negishi, N., Kutsuna, S., Ihara, T., Sugihara, S. and Takeuchi, K. (2000) Role of Oxygen Vacancy in the Plasma-Treated $\mathrm{TiO}_{2}$ Photocatalyst with Visible Light Activity for NO Removal. Journal of Molecular Catalysis A: Chemical, 161, 205-212. http://dx.doi.org/10.1016/S1381-1169(00)00362-9

[12] Borgarello, E., Kiwi, J., Gratzel, M., Pelizzetti, E. and Visca, M. (1982) Visible Light Induced Water Cleavage in Colloidal Solutions of Chromium-Doped Titanium Dioxide Particles. Journal of the American Chemical Society, 104, 2996-3002. http://dx.doi.org/10.1021/ja00375a010

[13] Choi, W., Termin, A. and Hoffmann, M.R. (1994) The Role of Metal Ion Dopants in Quantum-sized TiO ${ }_{2}$ : Correlation between Photoreactivity and Charge Carrier Recombination Dynamics. The Journal of Physical Chemistry, 98, 1366913679. http://dx.doi.org/10.1021/j100102a038

[14] Zang, L., Lange, C., Abraham, I., Storck, S., Maier, W.F. and Kisch, H. (1998) Amorphous Microporous Titania Modified with Platinum (IV) Chloride-A New Type of Hybrid Photocatalyst for Visible Light Detoxification. The Journal of Physical Chemistry B, 102, 10765-10771. http://dx.doi.org/10.1021/jp981755j

[15] Klosek, S. and Raftery, D. (2001) Visible Light Driven V-doped $\mathrm{TiO}_{2}$ Photocatalyst and its Photooxidation of Ethanol. The Journal of Physical Chemistry B, 105, 2815-2819. http://dx.doi.org/10.1021/jp004295e

[16] Asahi, R., Morikawa, T., Ohwaki, T., Aoki, K. and Taga, Y. (2001) Visible-Light Photocatalysis in Nitrogen-Doped Titanium Oxides. Science, 293, 269-271. http://dx.doi.org/10.1126/science.1061051

[17] Irie, H., Watanabe, Y. and Hashimoto, K. (2003) Nitrogen-Concentration Dependence on Photocatalytic Activity of $\mathrm{TiO}_{2-\mathrm{x}} \mathrm{N}_{\mathrm{x}}$ Powders. The Journal of Physical Chemistry B, 107, 5483-5486. http://dx.doi.org/10.1021/jp030133h

[18] Tachikawa, T., Tojo, S., Kawai, K., Endo, M., Fujitsuka, M., Ohno, T., Nishijima, K., Miyamoto, Z. and Majima, T. (2004) Photocatalytic Oxidation Reactivity of Holes in the Sulfur- and Carbon-Doped $\mathrm{TiO}_{2}$ Powders Studied by TimeResolved Diffuse Reflectance Spectroscopy. The Journal of Physical Chemistry B, 108, 19299-19306. http://dx.doi.org/10.1021/jp0470593

[19] Wang, H. and Lewis, J.P. (2005) Effects of Dopant States on Photoactivity in Carbon-Doped TiO 2 . Journal of Physics: Condensed Matter, 17, L209-L213. http://dx.doi.org/10.1021/jp0470593

[20] Chen, D., Jiang, Z., Geng, J., Wang, Q. and Yang, D. (2007) Carbon and Nitrogen Co-Doped TiO ${ }_{2}$ with Enhanced Visible-Light Photocatalytic Activity. Industrial \& Engineering Chemistry Research, 46, 2741-2746. http://dx.doi.org/10.1021/ie061491k

[21] Dong, F., Zhao, W. and Wu, Z. (2008) Characterization and Photocatalytic Activities of C, N and S Co-Doped TiO 2 with 1D Nanostructure Prepared by the Nano-Confinement Effect. Nanotechnology, 19, 365607-365616.

[22] Lettmann, C., Hildenbrand, K., Kisch, H., Macyk, W. and Maier, W.F. (2001) Visible Light Photodegradation of 4-Chlorophenol with a Coke-containing Titanium Dioxide Photocatalyst. Applied Catalysis B: Environmental, 32, 215227. http://dx.doi.org/10.1016/S0926-3373(01)00141-2

[23] Sakthivel, S. and Kisch, H. (2003) Daylight Photocatalysis by Carbon-Modified Titanium Dioxide. Angewandte Chemie International Edition, 42, 4908-4911. http://dx.doi.org/10.1002/anie.200351577

[24] Irie, H., Watanabe, Y. and Hashimoto, K. (2003) Carbon-Doped Anatase $\mathrm{TiO}_{2}$ Powders as a Visible-light Sensitive Photocatalyst. Chemistry Letters, 32, 772-773. http://dx.doi.org/10.1246/cl.2003.772

[25] Ohno, T., Tsubota, T., Nishijima, K. and Miyamoto, Z. (2004) Degradation of Methylene Blue on Carbonate SpeciesDoped $\mathrm{TiO}_{2}$ Photocatalysts under Visible Light. Chemistry Letters, 33, 750-751. http://dx.doi.org/10.1246/cl.2004.750

[26] Choi, Y., Umebayashi, T. and Yoshikawa, M. (2004) Fabrication and Characterization of C-Doped Anatase TiO 2 Photocatalysts. Journal of Materials Science, 39, 1837-1839. http://dx.doi.org/10.1023/B:JMSC.0000016198.73153.31

[27] Tseng, Y.H., Kuo, C.S., Huang, C.H., Li, Y.Y., Chou, P.W., Cheng, C.L. and Wong, M.S. (2006) Visible-Light-Responsive Nano- $\mathrm{TiO}_{2}$ with Mixed Crystal Lattice and Its Photocatalytic Activity. Nanotechnology, 17, 2490-2497. http://dx.doi.org/10.1088/0957-4484/17/10/009

[28] Yang, X., Cao, C., Hohn, K., Erickson, L., Maghirang, R., Hamal, D. and Klabunde, K. (2007) Highly Visible-Light Active C- and V-doped $\mathrm{TiO}_{2}$ for Degradation of Acetaldehyde. Journal of Catalysis, 252, 296-302. 
http://dx.doi.org/10.1016/j.jcat.2007.09.014

[29] Huang, Y., Ho, W., Lee, S., Zhang, L., Li, G. and Yu, J.C. (2008) Effect of Carbon Doping on the Mesoporous Structure of Nanocrystalline Titanium Dioxide and Its Solar-Light-Driven Photocatalytic Degradation of $\mathrm{NO}_{\mathrm{x}}$. Langmuir, 24, 3510-3516. http://dx.doi.org/10.1021/la703333z

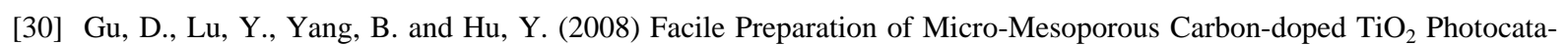
lysts with Anatase Crystalline Walls under Template-free Condition. Chemical Communications, 21, 2453-2455. http://dx.doi.org/10.1039/b800596f

[31] Dong, F., Wang, H. and Wu, Z. (2009) One-Step “Green” Synthetic Approach for Mesoporous C-Doped Titanium Dioxide with Efficient Visible Light Photocatalytic Activity. The Journal of Physical Chemistry C, 113, 16717-16723. http://dx.doi.org/10.1021/jp9049654

[32] Mai, L., Huang, C., Wang, D., Zhang, Z. and Wang, Y. (2009) Effect of C Doping on the Structural and Optical Properties of Sol-Gel $\mathrm{TiO}_{2}$ Thin Films. Applied Surface Science, 255, 9285-9289. http://dx.doi.org/10.1016/j.apsusc.2009.07.027

[33] Lin, X., Rong, F., Ji, X. and Fu, D. (2011) Carbon-Doped Mesoporous $\mathrm{TiO}_{2}$ Film and Its Photocatalytic Activity. Microporous and Mesoporous Materials, 142, 276-281. http://dx.doi.org/10.1016/j.micromeso.2010.12.010

[34] Zabek, P. and Kisch, H. (2010) Polyol-Derived Carbon-modified Titania for Visible Light Photocatalysis. Journal of Coordination Chemistry, 63, 2715-2726. http://dx.doi.org/10.1080/00958972.2010.491117

[35] Nishizawa, K., Miki, T., Suzuki, K. and Kato, K. (2003) Control of Crystallization and Crystal Orientation of AlkoxyDerived $\mathrm{SrBi}_{2} \mathrm{Ta}_{2} \mathrm{O}_{9}$ Thin Films by Ultraviolet Irradiation. Journal of Materials Research, 18, 899-907. http://dx.doi.org/10.1557/JMR.2003.0124

[36] Nishizawa, K., Miki, T., Suzuki, K. and Kato, K. (2005) Wavelength Dependence of Crystallization of Alkoxy-Derived $\mathrm{ZrO}_{2}$ Thin Films Prepared by Ultraviolet Irradiation. Journal of Materials Research, 20, 3133-3140. http://dx.doi.org/10.1557/JMR.2005.0392

[37] Nishizawa, K., Miki, T., Suzuki, K. and Kato, K. (2007) Photo-Assisted Crystallization of Zirconia Thin Films Prepared Using Chelate Compounds. Journal of Materials Research, 22, 2608-2616. http://dx.doi.org/10.1557/jmr.2007.0335

[38] Nishizawa, K., Miki, T., Suzuki, K. and Kato, K. (2007) Photo-Assisted Crystallization of Zirconia Thin Films and Their Electrical Evaluation. Thin Solid Films, 515, 4004-4010. http://dx.doi.org/10.1016/j.tsf.2006.10.006

[39] Okada, M., Yamada, Y., Jin, P., Tazawa, M. and Yoshimura, K. (2007) Two-Step Nitridation of Photocatalytic TiO 2 Films by Low Energy Ion Irradiation. Applied Surface Science, 254, 156-159. http://dx.doi.org/10.1016/j.apsusc.2007.07.011

[40] Pirson, A., Mohsine, A., Marchot, P., Michaux, B., Van Cantfort, O. and Pirard, J.P. (1995) Synthesis of $\mathrm{SiO}_{2}-\mathrm{TiO}_{2}$ Xerogels by Sol-Gel Process. Journal of Sol-Gel Science and Technology, 4, 179-185.

[41] Caruso, J., Roger, C., Schwertfeger, F., Hampden-Smith, M.J., Rheingold, A.L. and Yap, G. (1995) Solvent-Dependent Ester Elimination and Ligand Exchange Reactions between Trimethylsilyl Acetate and Tin (IV) Tetra-tert-Butoxide. Inorganic Chemistry, 34, 449-453. http://dx.doi.org/10.1021/ic00106a006

[42] Toyoda, M., Hamaji, Y. and Tomono, K. (1997) Fabrication of $\mathrm{PbTiO}_{3}$ Ceramic Fibers by Sol-Gel Processing. Journal of Sol-Gel Science and Technology, 9, 71-84.

[43] Lee, C.S., Kuo, C.N., Shao, M.Y. and Gau, H.M. (1999) Reactions of Ti(O-i-Pr)Cl $\mathrm{Cl}_{3}$ with Bidentate Ligands Containing Hydroxy and Methoxy Groups. The Crystal Structure of $\mathrm{Ti}(\mathrm{O}-\mathrm{i}-\mathrm{Pr}) \mathrm{Cl}_{3}\left(\mathrm{HOCH}_{2} \mathrm{CH}_{2} \mathrm{OCH}_{3}\right)$ and the ${ }^{1} \mathrm{H}$ Variable-Temperature NMR Studies of Solution Structures of Ti(O-i-Pr) $\mathrm{Cl}_{3}\left(\mathrm{HOCH}_{2} \mathrm{CH}_{2} \mathrm{OCH}_{3}\right)$ and $\mathrm{Ti}(\mathrm{O}-\mathrm{i}-\mathrm{Pr}) \mathrm{Cl}_{3}\left(\mathrm{CH}_{3} \mathrm{OCH}_{2} \mathrm{CH}_{2} \mathrm{OCH}_{3}\right)$. Inorganica Chimica Acta, 285, 254-261. http://dx.doi.org/10.1016/S0020-1693(98)00348-X

[44] Knolker, H.J., Goesmann, H. and Klauss, R. (1999) A Novel Method for the Demetalation of Tricarbonyliron-Diene Complexes by a Photolytically Induced Ligand Exchange Reaction with Acetonitrile. Angewandte Chemie International Edition, 38, 702-705. http://dx.doi.org/10.1002/(SICI)1521-3773(19990301)38:5<702::AID-ANIE702>3.0.CO;2-W

[45] Bokach, N.A., Haukka, M., Hirva, P., Fatima, M., Silva, C.G.D., Kukushkin, V.Y. and Pombeiro, A.J.L. (2006) Photoinduced Synthesis and Electrochemical Properties of New Ruthenium(mono)bipyridine Dialkylcyanamide and Propiononitrile Complexes. Journal of Organometallic Chemistry, 691, 2368-2377. http://dx.doi.org/10.1016/j.jorganchem.2005.12.064

[46] Vos, J.G. and Pryce, M.T. (2010) Photoinduced Rearrangements in Transition Metal Compounds. Coordination Chemistry Reviews, 254, 2519-2532. http://dx.doi.org/10.1016/j.ccr.2010.04.010

[47] Garner, R.N., Joyce, L.E. and Turro, C. (2011) Effect of Electronic Structure on the Photoinduced Ligand Exchange of 
Ru(II) Polypyridine Complexs. Inorganic Chemistry, 50, 4384-4391. http://dx.doi.org/10.1021/ic102482c

[48] Theophanides, T. and Harvey, P.D. (1987) Structural and Spectroscopic Properties of Metal-Urea Complexes. Coordination Chemistry Reviews, 76, 237-264. http://dx.doi.org/10.1016/0010-8545(87)85005-1

[49] Li, J.G., Yang, X. and Ishigaki, T. (2006) Urea Coordinated Titanium Trichloride Ti ${ }^{\mathrm{III}}\left[\mathrm{OC}(\mathrm{NH})_{2}\right]_{6} \mathrm{Cl}_{3}$ : A Single Molecular Precursor Yielding Highly Visible Light Responsive $\mathrm{TiO}_{2}$ Nanocrystallites. Journal of Physical Chemistry B, 110, 14611-14618. http://dx.doi.org/10.1021/jp0620421

[50] Azouani, R., Tieng, S., Chhor, K., Bocquet, J.F., Eloy, P., Gaigneaux, E.M., Klementiev, K. and Kanaev, A.V. (2010) $\mathrm{TiO}_{2}$ Doping by Hydroxyurea at the Nucleation Stage: Towards a New Photocatalyst in the Visible Spectral Range. Physical Chemistry Chemical Physics, 12, 11325-11334. http://dx.doi.org/10.1039/b923548e

[51] Linsebigler, A.L., Lu, G. and Yates Jr., J.T. (1995) Photocatalysis on $\mathrm{TiO}_{2}$ Surfaces: Principles, Mechanisms, and Selected Results. Chemical Reviews, 95, 735-758. http://dx.doi.org/10.1021/cr00035a013

[52] Egerton, T.A. and Tooley, I.R. (2004) Effect of Changes in $\mathrm{TiO}_{2}$ Dispersion on Its Measured Photocatalytic Activity. Journal of Physical Chemistry B, 108, 5066-5072. http://dx.doi.org/10.1021/jp0378992 